\title{
Traduzindo uma história de Hebel
}

João Cândido Cartocci Maia ${ }^{1}$

Resumo: Pretende-se comentar as soluções adotadas para a tradução de uma pequena narrativa de Johann Peter Hebel (1760-1826), "Reencontro inesperado" (“Unverhofftes Wiedersehen”), de 1811. As soluções de tradução dependeram de uma interpretação da história a ser traduzida, que foi fortemente inspirada na leitura feita por Walter Benjamin (1892-1940). Faremos referência, sobretudo, às considerações feitas pelo crítico no célebre ensaio sobre "O narrador" e na conferência de rádio proferida em 1929, intitulada "Johann Peter Hebel".

Palavras-chave: Johann Peter Hebel; Unverhofftes Wiedersehen; Reencontro inesperado; Walter Benjamin.

\section{Introdução}

Apresentaremos, a seguir, uma das mais conhecidas narrativas de Johann Peter Hebel; "a mais bela história do mundo" nas palavras do filósofo alemão Ernst Bloch. Figura no livro Caixinha de tesouros do amigo da familia renana (Schatzkästlein des rheinischen Hausfreundes), publicado em 1811, mas que reúne textos que Hebel ia publicando no almanaque oficial de Baden desde 1807, quando assumiu o posto de redator da publicação. Em seguida, apresentaremos um comentário sobre a tradução, necessário para se discutir os momentos da conversão do texto para o português em que se tornava patente a dupla tarefa do tradutor de interpretar seu material e de conhecer o meio em que ele circulava originalmente. Não faremos, portanto, uma análise literária da história de Hebel, mas nos reportaremos a ar-

1 Graduando em Letras na Universidade de São Paulo. 
gumentos que a crítica - sobretudo a de Walter Benjamin - construiu em torno das narrativas de Hebel e que permitiram que o tradutor tomasse uma ou outra decisão ao transpor "Reencontro inesperado" para o português.

Cumpre, antes, dizer uma palavrinha sobre Johann Peter Hebel, escritor tão importante da narrativa em prosa alemã, mas pouco conhecido entre nós. ${ }^{2}$ Nascido em uma família de artesãos e camponeses, Hebel trilhou um caminho ligado à vida intelectual e religiosa. Teve formação clássica e luterana e cursou teologia. Atuou como professor e pastor e também sempre se dedicou, com maior ou menor intensidade, à produção literária. Em 1791, tornou-se professor de letras clássicas em Karlsruhe; em 1803, publicou seu primeiro livro, uma antologia de Poemas alemânicos, escrito em língua dialetal; e em 1807 foi nomeado o responsável pelo almanaque oficial de Baden, para o qual começou a escrever histórias, entre as quais a que aqui apresentamos. A publicação obteve enorme sucesso e deu origem a uma antologia que continha uma seleção das narrativas de Hebel: o Florilégio ou Caixinha de tesouros do amigo da família renana (Schatžkëstlein des rheinischen Hausfreundes). O almanaque continuou sendo publicado até 1815. Um último número saiu em 1819 depois de um período em que Hebel ficara afastado da direção da publicação. Johann Peter Hebel morreu em 1826. Seu último trabalho foram versões infantis das Histórias biblicas (Biblische Geschichten), que saíram em livro em 1824.

Esta tradução foi possível graças às portas abertas pelo curso de graduação ministrado, no primeiro semestre de 2020, pela professora Magdalena Nowinska, a quem agradeço a orientação e o estímulo. Devo igualmente às sugestões de Telma Franco Diniz para estes comentários, a quem também agradeço.

2 Para um histórico das poucas vezes em que Hebel esteve disponível ao leitor brasileiro, conferir a introdução que Samuel Titan Jr. fez as suas próprias traduções em "O almanaque de Johann Peter Hebel”. Novos estud.-CEBRAP, São Paulo, n. 72, p. 233-242, Julho-2005. Disponível em http://www.scielo.br/ scielo.php?script=sci_arttext\&pid=S0101-33002005000200016\&lng=en\&nrm=iso Acesso em 14 ago. 2020. 


\section{Reencontro inesperado}

\section{Tradução de João Cândido Cartocci Maia}

Em Falun na Suécia, uns bons cinquenta anos atrás ou mais, um jovem mineiro beijou sua jovem e bela noiva e lhe disse: "No dia de Santa Lúcia nosso amor será abençoado pela mão do pastor. Então seremos marido e mulher e vamos construir um ninhozinho só nosso." "E lá a paz e o amor devem morar", disse a bela noiva, com um sorriso doce, "porque você é tudo que tenho, e sem você eu prefiro estar no túmulo do que em qualquer outro lugar.” Mas quando, pela segunda vez antes do dia de Santa Lúcia, o padre anunciou à Igreja: "se alguém se opõe a este matrimônio que fale agora ou cale-se para sempre", a morte pediu a palavra. Pois o jovem, num outro dia, em seu negro traje de mineiro - o mineiro sempre porta seu sudário -, passou pela casa da noiva, bateu na janela ainda uma vez e lhe disse bom-dia, mas nunca mais disse boa-noite. Ele nunca mais voltou da mina, e ela costurou para ele, em vão, toda manhã, um lenço preto de bordas vermelhas, para o casamento, mas como ele nunca voltou, deixou isso de lado e chorou e dele nunca se esqueceu. De lá para cá, a cidade de Lisboa em Portugal foi destruída durante um terremoto, e a Guerra dos Sete Anos terminou, e o Imperador Francisco I morreu, e a Ordem dos Jesuítas foi dissolvida e a Polônia repartida, e a Imperatriz Maria Teresa morreu, e Struensee foi executado, a América ficou livre, e os poderes franceses e espanhóis unidos não puderam conquistar Gibraltar. Os turcos encurralaram o General Stein na Cova dos Veteranos na Hungria, e o Imperador José também morreu. O Rei Gustavo da Suécia conquistou a Finlândia russa, e a Revolução Francesa e a longa guerra começaram, e o Imperador Leopoldo Segundo também foi para o túmulo. Napoleão conquistou a Prússia, e os ingleses bombardearam Copenhague, e os camponeses plantavam e colhiam. O moleiro moía, e o ferreiro martelava, e os mineiros escavavam pelas terras férreas nas suas oficinas subterrâneas. Mas os mineiros, em Falun, no ano de 1809, um pouco antes ou depois da Noite de São João, querendo abrir uma passagem entre dois poços, a bons trezentos côvados abaixo da superfície desenterraram dos detritos e do vitríolo o corpo de um jovem, todo penetrado por sulfato terroso, que entretanto estava completamente intocado e inalterado; assim era de todo possível reconhecer seu rosto e sua idade, como se ele se tivesse acabado de morrer, há uma hora, ou dormido um pouco no trabalho. Mas quando foi trazido à luz do dia, pai e mãe, amigos e conhecidos, já estavam, há muito, mortos; ninguém sabia do jovem adormecido ou qualquer coisa sobre sua desgraça, até que a antiga amada do mineiro, que uma vez esteve na superfície mas nunca mais voltara, chegou. Cinza e corcunda, ela se aproximou com uma bengala ao lugar em que ele estava, e reconheceu seu noivo; e, mais com encanto amoroso do que com dor, ela caiu sobre o cadáver amado e, assim que acalmou os impulsos da alma, "é meu noivo", disse finalmente, "pelo qual estou de luto há longos cinquenta anos e que Deus me deixou ver mais uma vez 
antes do meu fim. Oito dias antes do casamento, ele foi para debaixo da terra e nunca mais retornou." Naquele momento os corações de todos os circundantes foram tomados por lágrimas e melancolia, ao verem a então noiva agora na figura da velhice, definhada e sem forças, e o noivo ainda em sua beleza juvenil, e como no peito dela depois de cinquenta anos a chama do amor juvenil era ainda uma vez despertada, sem que ele abrisse a boca para sorrir ou os olhos para vê-la; e ela, a única que lhe pertencera e que tinha direitos sobre ele, finalmente pediu que ele fosse deixado pelos mineiros em sua casinha, até que seu túmulo estivesse preparado no cemitério. No dia seguinte, quando o túmulo estava preparado no cemitério e os mineiros o vieram buscar, ela abriu uma caixinha, pôs-lhe o lenço preto com bordas vermelhas e em seguida o acompanhou em suas roupas de domingo, como se fosse o dia do casamento dela e não o do funeral dele. Então, enquanto estendiam-lhe no túmulo, no cemitério, ela disse: "Durma bem agora, um ou dez dias, no fresco leito nupcial, e não deixe que o tempo te seja longo. Tenho ainda pouco a fazer e venho logo, e logo será um novo dia. - O que a terra uma vez devolveu, ela não tirará uma segunda vez.", disse ela, indo embora, olhando para trás.

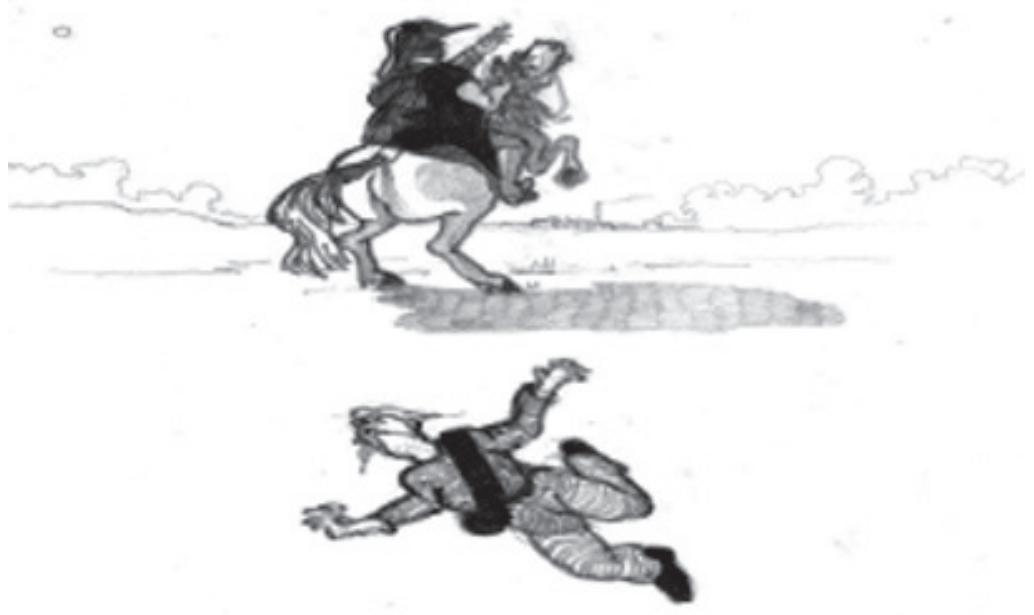

[Figura 1. Júlio de Campos Andrade Lamparelli. "De lá pra cá”. Especial para esta tradução, 2020] 


\section{Unverhofftes Wiedersehen}

Johann Peter Hebel

In Falun in Schweden küsste vor guten fünfzig Jahren und mehr ein junger Bergmann seine junge hübsche Braut und sagte zu ihr: »Auf Sankt Luciä wird unsere Liebe von des Priesters Hand gesegnet. Dann sind wir Mann und Weib und bauen uns ein eigenes Nestlein.«»Und Friede und Liebe soll darin wohnen«, sagte die schöne Braut mit holdem Lächeln, »denn du bist mein Einziges und Alles, und ohne dich möchte ich lieber im Grab sein als an einem andern Ort. « Als sie aber vor St. Luciä der Pfarrer zum zweiten Male in der Kirche ausgerufen hatte: »So nun jemand Hindernis wusste anzuzeigen, warum diese Personen nicht möchten ehelich zusammenkommen «, da meldete sich der Tod. Denn als der Jüngling den andern Morgen in seiner schwarzen Bergmanns-kleidung an ihrem Haus vorbei ging, der Bergmann hat sein Totenkleid immer an, da klopfte er zwar noch ein-mal an ihrem Fenster und sagte ihr guten Morgen, aber keinen guten Abend mehr. Er kam nimmer aus dem Bergwerk zurück, und sie saumte vergeblich selbigen Morgen ein schwarzes Halstuch mit rotem Rand für ihn zum Hochzeittag, sondern als er nimmer kam, legte sie es weg und weinte um ihn und vergaß ihn nie. Unterdessen wurde die Stadt Lissabon in Portugal durch ein Erdbeben zerstört, und der Siebenjährige Krieg ging vorüber, und Kaiser Franz der Erste starb, und der Jesuitenorden wurde aufgehoben und Polen geteilt, und die Kaiserin Maria Theresia starb, und der Struensee wurde hingerichtet, Amerika wurde frei, und die vereinigte französische und spanische Macht konnte Gibraltar nicht erobern. Die Türken schlossen den General Stein in der Veteraner Höhle in Ungarn ein, und der Kaiser Joseph starb auch. Der König Gustav von Schweden eroberte russisch Finnland, und die französische Revolution und der lange Krieg fing an, und der Kaiser Leopold der Zweite ging auch ins Grab. Napoleon eroberte Preußen, und die Engländer bombardierten Kopenhagen, und die Ackerleute säeten und schnitten. Der Müller mahlte, und die Schmiede hämmerten, und die Bergleute gruben nach den Metalladern in ihrer unterirdischen Werkstatt. Als aber die Bergleute in Falun im Jahr 1809 etwas vor oder nach Johannis zwischen zwei Schachten eine Öffnung durchgraben wollten, gute dreihundert Ellen tief unter dem Boden, gruben sie aus dem Schutt und Vitriolwasser den Leichnam eines Jünglings heraus, der ganz mit Eisenvitriol durchdrungen, sonst aber unverwest und unverändert war, also dass man seine Gesichtszüge und sein Alter noch völlig erkennen konnte, als wenn er erst vor einer Stunde gestorben oder ein wenig eingeschlafen wäre an der Arbeit. Als man ihn aber zu Tag ausgefördert hatte, Vater und Mutter, Gefreundte und Bekannte waren schon lange tot, kein Mensch wollte den schlafenden Jüngling kennen oder etwas von seinem Unglück wissen, bis die ehemalige Verlobte des Bergmanns kam, der eines Tages auf die Schicht gegangen war und nimmer zurückkehrte. Grau und zusammengeschrumpft kam sie an einer Krücke an den Platz und erkannte ihren Bräutigam; und mehr mit freudigem 
Entzücken als mit Schmerz sank sie auf die geliebte Leiche nieder, und erst als sie sich von einer langen heftigen Bewegung des Gemüts erholt hatte, »es ist mein Verlobter«, sagte sie endlich, »um den ich fünfzig Jahre lang getrauert hatte und den mich Gott noch einmal sehen lässt vor meinem Ende. Acht Tage vor der Hochzeit ist er auf die Grube gegangen und nimmer gekommen.« Da wurden die Gemüter aller Umstehenden von Wehmut und Tränen ergriffen, als sie sahen die ehemalige Braut jetzt in der Gestalt des hingewelkten kraftlosen Alters und den Bräutigam noch in seiner jugendlichen Schöne, und wie in ihrer Brust nach fünfzig Jahren die Flamme der jugendlichen Liebe noch einmal erwachte; aber er öffnete den Mund nimmer zum Lächeln oder die Augen zum Wiedererkennen; und wie sie ihn endlich von den Bergleuten in ihr Stüblein tragen ließ, als die einzige, die ihm angehöre und ein Recht an ihn habe, bis sein Grab gerüstet sei auf dem Kirchhof. Den andern Tag, als das Grab gerüstet war auf dem Kirchhof und ihn die Bergleute holten, schloss sie ein Kästlein auf, legte sie ihm das schwarzseidene Halstuch mit roten Streifen um und begleitete ihn in ihrem Sonntagsgewand, als wenn es ihr Hochzeittag und nicht der'Tag seiner Beerdigung wäre. Denn als man ihn auf dem Kirchhof ins Grab legte, sagte sie: »Schlafe nun wohl, noch einen Tag oder zehn im kühlen Hochzeitbett, und lass dir die Zeit nicht lang werden. Ich habe nur noch wenig zu tun und komme bald, und bald wird's wieder Tag. Was die Erde einmal wiedergegeben hat, wird sie zum zweiten Male auch nicht behalten«, sagte sie, als sie fortging und noch einmal umschaute. 


\section{Comentário da tradução}

Comumente, os tradutores valem-se de notas explicativas para situar o leitor ante alguma passagem, palavra ou referência obscura, que não seria, sem o auxílio do comentário, bem compreendida ou mesmo devidamente compreendida. São os casos, por exemplo, das palavras intraduzíveis ou das que encerram noções importantes na obra de tal ou qual autor, as quais devem ser comentadas e justificadas quando convertidas para uma nova língua, o que o tradutor não faz sem um conhecimento seguro do pensamento, das noções, e dos conceitos mobilizados pelo autor que ele traduz. Há vezes ainda em que o tradutor precisa puxar uma nota para explicar a referência feita a personagens, lugares ou eventos que, desconhecidos, dificultariam ou mesmo inviabilizaram ao leitor da "língua de chegada" o acesso à intenção pretendida pelo autor quando mencionou, justamente, uma personagem, um lugar ou um evento. O texto de Hebel é cheio de nomes de personagens históricos, eventos e lugares. Mas não colocamos notas explicativas, o que também é uma escolha de tradução, que devemos justificar. A ausência de notas explicativas pode tornar obscuras as referências que Hebel faz na sua crônica histórica, que indica a passagem dos cinquenta anos que se passaram entre a morte do mineiro e a redescoberta de seu corpo. Mas é precisamente o desconhecimento das personagens históricas e dos lugares que reproduz, com mais fidelidade, a posição do leitor visado por Hebel. É verdade que Hebel, ao ter escrito essa longa sucessão de fatos históricos, revelou-se um homem atualizado, a par dos grandes eventos que marcaram sua época; é também verdade que o sucesso de suas histórias fizeram-no extrapolar o universo provinciano de Baden a ponto de ter seus textos circulando entre grandes intelectuais e artistas do tempo - Goethe, para mencionar apenas um, que também certamente não passou batido pelos acontecimentos que agitaram a era moderna. Mas o leitor primeiro de Hebel não era esse: não era como ele, um pastor e filantropo, impactado pela Revolução Francesa, versado no iluminismo, leitor de Jean-Paul e dos escritores libertinos franceses. ${ }^{3}$ Se recorrermos a uma anotação feita por Walter Benjamin em que está recolhida uma passagem de Berthold Auerbach, podemos entrever

3 Essas informações são de Walter Benjamin e podem ser consultadas em uma conferência que ele proferiu na rádio Südwestdeutscher Rundfunk a 29 de outubro de 1929, transcrita em BENJAMIN, Walter. Gesammelte Schriften, tomo II - 2. Frankfurt am Main: Suhrkamp Verlag, 1977, p. 638. Para versão em inglês, „Johann Peter Hebel“ em BENJAMIN, Walter. The storyteller essays. LEWIS, Tess, (Trad.). TITAN, Samuel (Org.). Apple Books, n.p. 
o leitor pretendido por Hebel. Como é uma passagem muito especial, citaremos integralmente:

\begin{abstract}
“Comentário muito bonito de Auerbach: 'Como é' então 'um florilégio geralmente lido nos círculos populares? Depois do dia de trabalho, a família se reúne à noite, o assunto da conversa se esgota; então o pai busca um livro ou almanaque, estende-o para um de seus filhos que ainda frequenta a escola ou o catecismo e diz: 'Leia em voz alta, meus olhos não estão mais acostumados a ler, etc.' Pela boca da criança, em comunhão com todos os membros da casa, o que o escritor oferece torna-se, então, voz alta; não é necessário que tudo seja compreendido pela criança (e as crianças gostam de ler até mesmo escritos que contêm muito do que não é imediatamente evidente para elas); contudo, toda matéria e forma inadequadas emergem de maneira ainda mais evidente pela boca da criança. [...]"'4 (grifo meu). (BENJAMIN, 1977, p. 1444)
\end{abstract}

As considerações de Auerbach recolhidas por Benjamin estão em linha com as explicações que Rolf Max Kully oferece, no seu excelente "manual", sobre o leitor visado por Hebel. Camponês, não devia ter outro livro em sua casa além da Bíblia, e quando recorria à leitura do almanaque, após longas horas de trabalho, queria tirar-lhes algum proveito prático, como um conselho. ${ }^{5}$ De modo algum queremos com isso insinuar a total ignorância do público de Hebel, mas ressaltar apenas, como Auerbach, que não é literariamente necessário conhecer todas as referências do escritor. Por isso, e tendo em vista o leitor histórico de Hebel, não explicamos, destrinchando em notas, todo o conteúdo histórico mobilizado na narrativa. Pela mesma razão, traduzimos os nomes dos locais e das personagens históricas, que, não sendo todos alemães, Hebel também converteu para a língua de seus leitores. ${ }^{6}$

Mas qual é, então, a relação entre o autor esclarecido e seu leitor, isto é, o leitor pobre, como faz questão de ressaltar Benjamin a fim de dissipar o tabu em torno da questão da pobreza em literatura? A poesia especial de Hebel jaz,

4 Cf. o complemento que a edição dos Escritos reunidos de Benjamin fez à conferência de rádio: id., ibid.

5 KULLY, Rolf Max, Johann Peter Hebel. J.B.Metzlersche Verlagsbuchhandlung, Stuttgart, 1969, pp. 54-55.

6 Dessa maneira, estamos traduzindo também de acordo com os princípios estabelecidos por Christiane Nord. Para a teórica da tradução, o texto traduzido deve refletir, na medida em que for possível dentro de uma conversão para uma nova língua, "os fatores extratextuais da situação na qual o texto é utilizado", em que sobressaiam os fins comunicativos visados pelo autor ante todos os participantes implicados na circulação do texto. NORD, C. Análise textual em tradução: bases teóricas, métodos e aplicação didática. E. Zipse. São Paulo: Rafael Copetti Editor, 2016 p. 198. Cf. também pp. 73-76. 
precisamente, nessa relação, isto é, no modo como sua narrativa articula o macrocosmo dos acontecimentos modernos, ao qual a cultura esclarecida lhe dava acesso, ao microcosmo da vida provinciana de seus leitores, os camponeses e a pequena burguesia de Baden, entre os quais ele mesmo, muitas vezes, viu-se confinado. Ante seu público, Hebel não se portava como um professor de escola ou com um historiador, preocupado com transmissão digamos científica dos acontecimentos. Seu segredo encontrava-se, na verdade, na capacidade de narrar os eventos históricos conferindo-lhes a dimensão concreta da vida de quem lia suas histórias. Dizendo de outro modo, a maestria de Hebel era preencher, com o aqui e agora da vida de seu público, os acontecimentos históricos que de outra maneira lhe ficariam alheios no tempo e no espaço. E é sob o signo da morte que Hebel pôde inscrever, no plano histórico, a história de suas personagens - com os quais deveriam se identificar seus leitores. ${ }^{7}$ De fato, a presença da morte está na referência aos poderosos, nos conflitos armados ou nos desastres naturais e está também na vida dos pobres, obrigados pelo trabalho, a viver na lida direta com a natureza, que é o que leva embora o mineiro. Impossível não dizer também que é da consciência da morte que a noiva, já velha, extrai seu belo, sábio desencanto. Assim, é tomando a morte como presença comum que Hebel é capaz de dar concretude à passagem dos cinquenta anos por que a noiva espera seu noivo: a morte do mineiro e a longa espera ensejam, no plano da narrativa, a crônica histórica e essa, por sua vez, com a maior naturalidade, passa de volta ao mundo provinciano dos trabalhadores pobres:

“[...] Napoleão conquistou a Prússia, e os ingleses bombardearam Copenhague, e os camponeses plantavam e colhiam. O moleiro moía, e o ferreiro martelava, e os mineiros escavavam pelas terras férreas nas suas oficinas subterrâneas. Mas os mineiros, em Falun [...]"

Mas mesmo que marcados pela morte, o plano dos eventos da era moderna e o da vida dos trabalhadores guardam diferenças significativas. Um traz acontecimentos encerrados em si mesmos, particularizados, com lugar e nomes próprios; outro, o trabalho de gerações, anônimo e reiterado. Nesse ponto específico, o

7 A ideia de que Hebel deriva da experiência da morte a autoridade para contar suas histórias é uma ideia que está presente tanto na conferência de rádio já mencionada, quanto no décimo primeiro excerto do ensaio sobre "O narrador". Cf. respectivamente, GS, II-2, pp. 636-637 e BENJAMIN, Walter. Obras escolbidas, vol, 1: Magia e técnica, arte e política. $3^{\mathrm{a}}$ ed. ROUANET, Sérgio Paulo (Trad.). GAGNEBIN, Jeanne Marie (Pref.). São Paulo, Editora Brasiliense, 1987, pp. 208-209. 
tradutor será obrigado a interpretar e a tomar uma decisão, pois a língua alemã, no registro escrito, não diferencia, como no português, acontecimentos distendidos no passado - que indicamos com o pretérito imperfeito - e acontecimentos pontuais, acabados - que indicamos com pretérito perfeito. No alemão, os dois planos narrados são contados com o mesmo tempo verbal, o que torna menos brusca a passagem de um para o outro. Como é assim, temos de justificar, no trecho acima, a transição de modo verbal que fizemos. A escolha baseou-se no ritmo de Hebel, na cadência de sua frase.

Reparando bem, vemos que, para narrar vida dos noivos e de sua vila, o narrador de Hebel elabora frases longas, cheias de conteúdo, ${ }^{8}$ que além de serem uma possibilidade do alemão, são próprias da contação oral de histórias, que têm direito a repetições e a interrupções da ação para avaliações das personagens. Por vezes, tais personagens são acompanhadas tão de perto que a frase mesma parece seguir seu movimento. Além disso, essas frases traduzem uma experiência especial da passagem tempo, como se por elas fosse transmitida uma distensão do fluxo temporal. Para isso, contribuem as estruturas extremamente temporalizadas da sintaxe - "mas quando...", "enquanto...", “como..." -, presentes em todo o texto, e que, sobretudo quando têm valor adversativo, tensionam a temporalidade, cujo curso não depende apenas das ações, mas sobretudo das vicissitudes por que passam as personagens. (Faremos apenas uma ressalva: não se deve associar Hebel apenas ao contador de histórias, mas, como dissemos, é preciso considerá-lo sempre pairando entre a cultura popular e a sua formação erudita. Por isso, é provável que para sua construção frasal também tenham contribuído seus conhecimentos em retórica e em estilística latina. $)^{9}$

Se é a distensão temporal que caracteriza o modo como a vida dos pobres é contada, é de outra forma, com outra cadência frasal que se conta o interregno histórico. Os acontecimentos temporais pontuais, já acabados, só podem ser agrupados por justaposição. Para contá-los, o narrador não estabelece relações de causa e efeito, como a maneira do historiador profissional e acadêmico. A relação que os eventos históricos estabelecem entre si não devem, nessa história de Hebel, ser buscada na sua própria relação consigo mesmos, mas decifradas à luz do

8 Frases que podem acolher até mesmo falas de personagens. Não é costume em língua portuguesa deixar entre aspas o que as personagens falam e inseri-las no curso da prosa do narrador. Mas como no caso de Hebel o efeito da narração vale-se muito dessa incorporação, preferimos manter as falas nesse contexto em vez de segmentá-las com travessões e mudanças de linha.

9 KULLY, 1969, p. 47. 
longo calvário do trabalho atravessado por gerações e gerações de trabalhadores pobres. É essa longa duração do trabalho, que permaneceu intacta apesar da sucessão de eventos, que aqui transmitimos com o imperfeito: "[...] o moleiro moía, e o ferreiro martelava, e os mineiros escavavam pelas terras férreas nas suas oficinas subterrâneas." Acreditamos que isso nos permite realizar, com maior naturalidade, a transição dos eventos históricos prontos, acabados e justapostos, para aquela distensão temporal que caracteriza o modo como o narrador acompanha a noiva já velha. O imperfeito é o tempo mais apropriado no português para falar das ações continuadas no tempo - como o trabalho dos mineiros, que continuou antes e depois dos eventos históricos mencionados -, além de oferecer algo como um meio termo que tornaria menos brusca a passagem entre o pretérito perfeito, pontual, e a distensão temporal das frases "mas... quando", usadas pelo narrador para acompanhar a velha noiva.

Para acabar, dois apontamentos finais: um sobre terminologia e outro sobre o modo por que uma expressão foi traduzida. Quanto ao primeiro, o leitor notou que, quando os mineiros, no ano de 1809, encontram o corpo do noivo já petrificado pelo vitríolo, eles o acharam a "bons trezentos côvados abaixo da terra". O côvado é uma unidade de medida em desuso, de modo que uma solução de tradução poderia ser tê-la convertido para o sistema métrico. Mas mesmo essa operação seria problemática. O côvado é uma medida muito antiga e que varia de lugar para lugar. $\mathrm{O}$ autor não especifica, mas é de se supor que ele se referisse ao côvado renano (rheinische Elle), que corresponde a 61 centímetros. Todavia, mais importante ainda é, simplesmente, o fato de que a precisão métrica não era visada por Hebel. Seu narrador não diz "a trezentos côvados", mas "a bons trezentos côvados" e basta para entender que o mineiro estava enterrado em um lugar bem fundo. Pensando bem, o próprio modo por que Hebel marca o tempo não é exato: "uns bons cinquenta anos atrás ou mais", "um pouco antes ou depois da Noite de São João". A imprecisão é uma das marcas que voz narrativa imprime nos eventos, ao situá-los no tempo e no espaço. Como diz Benjamin, não é próprio da narrativa

transmitir o 'puro em si' da coisa narrada como uma informação ou um relatoório. Ela mergulha a coisa na vida do narrador para em seguida retirá-la dele. Assim se imprime na narrativa a marca do narrador, como a mão do oleiro na argila do vaso. ${ }^{10}$

10 BENJAMIN, 1987, p. 205. 
E como Hebel não está fazendo um relatório científico, mas narrando, preferimos deixar o "impreciso" côvado, que além do mais guarda algo do universo provinciano, anterior a generalização do padrão métrico de 1875, quando as unidades de medida deixaram de variar de região para região. Finalmente, quanto à tradução de uma expressão, estamos nos referindo à tentativa de buscar o correlato em português de um frase feita do alemão, que pudesse, justamente, transmitir o efeito daqueles ditos que todo mundo conhece. Na versão original, o padre diz: "So nun jemand Hindernis wusste anzuzeigen, warum diese Personen nicht möchten ehelich zusammenkommen", que corresponde ao que o padre deve dizer ao celebrar o casamento, conforme a versão alemã do Livro de Oraşão Comum (Buch des gemeinsamen Gebetes). Sendo um livro cristão com versões em muitas línguas, bastava recorrer à versão em português, que todos conhecemos e que diz "se alguém se opõe a este matrimônio que fale agora ou cale-se para sempre".

A título de conclusão, queremos ressaltar apenas que a leitura de um grande autor é sempre cheia de perplexidades, as quais invariavelmente dependem, de um modo ou de outro, do modo pelo qual suas obras se colocaram em seu tempo e em seu meio. Com Hebel não é diferente. Esperamos que com essa tradução tenha sido possível recuperar o que era decisivo para trazer ao leitor brasileiro contemporâneo o que julgamos ser mais especial em sua narrativa. Esse trabalho não se faz sem pesquisa. De resto, é impossível reescrever "Reencontro inesperado" fora daquela Baden provinciana no período imediatamente posterior à Revolução Francesa, sem ser alemão e, sobretudo, sem ser Hebel.

\section{Referências bibliográficas}

BENJAMIN, Walter. Gesammelte Schriften, tomo II - 2. Frankfurt am Main: Suhrkamp Verlag, 1977, p. 638.

. Obras escolbidas, vol, 1: Magia e técnica, arte e politica. $3^{\mathrm{a}}$ ed. ROUANET, Sérgio Paulo (Trad.). GAGNEBIN, Jeanne Marie (Pref.). São Paulo, Editora Brasiliense, 1987, pp. 208-209.

. The storyteller essays. LEWIS, Tess, (Trad.). TITAN, Samuel (Org.). Apple Books, n.p. HEBEL, Johann Peter. Werke. Zwei Bände; hrsg. v. Otto Behagel, Stuttgart 1883-1884 (= Kürschners Deutsche National-Literatur Bd. 142/1 und 142/2) Bd.2: Schatzkëstlein des rheinischen Hausfreundes, 1884; Disponível em: < http://gutenberg.spiegel.de/buch/johannpeter-hebel-schatzk-329/90>. Acesso em 28 jul. 2020.

KULLY, Rolf Max, Johann Peter Hebel. J.B.Metzlersche Verlagsbuchhandlung, Stuttgart, 1969. 
NORD, C. Análise textual em tradução: bases teóricas, métodos e aplicação didática. E. Zipse. São Paulo: Rafael Copetti Editor, 2016.

TITAN JR., Samuel. "O almanaque de Johann Peter Hebel". In.: Novos estud.-CEBRAP, São Paulo, n. 72, p. 233-242, Julho-2005. Disponível em: <http://www.scielo.br/scielo. php?script $=$ sci_arttext\&pid $=$ S0101-33002005000200016\&lng $=$ en\&nrm $=$ iso $>$. Acesso em 28 jul. 2020. 